\title{
Cambios demográficos y epidemiológicos en Colombia durante el siglo XX
}

\author{
Jaime Carmona-Fonseca \\ Facultad de Medicina, Grupo Malaria, Universidad de Antioquia, Medellín, Colombia.
}

Introducción. Las actividades de investigación, docencia, planificación y administración en salud requieren disponer de un panorama demográfico y epidemiológico actualizado, que dé cuenta de los cambios y tendencias.

Objetivo. Describir los principales cambios demográfico-epidemiológicos de Colombia en el siglo XX, así como las proyecciones a corto plazo.

Materiales y métodos. Estudio descriptivo, longitudinal, con información secundaria.

Resultados. La población pasará de 4'737.588 habitantes en 1905 a 53 millones en 2015. De una verdadera pirámide presente hasta 1951, la distribución de la población pasó a una figura deformada (entre 0 y 14 años no existe diferencia apreciable). Entre 1905 y 1938, la natalidad era de $43 \%$ y, a finales de 2005, será de 22\%. La mortalidad pasó de 23\% entre 1905 y 1912 a $6 \%$ entre 1985 y 1993, pero subirá a 8,3\% en 2010. La mortalidad infantil también estaba reduciéndose en el decenio de 1930, pero su nivel todavía era muy alto, y apenas a comienzos del decenio de 1960 empezó a caer acentuadamente. En 1938, la población en cabeceras municipales era de $31 \%$ y en 2000 de $72 \%$. La mortalidad por causas cambió significativamente después de 1950. Las enfermedades infecciosas-parasitarias y perinatales, principales causas de muerte hasta finales del decenio de 1960 a 1969, perdieron importancia frente a enfermedades degenerativas, accidentes y homicidios, que ahora predominan.

Conclusión. Nuestra actual densidad de población es relativamente baja. Más importante que el cambio demográfico cuantitativo es su gran velocidad. El envejecimiento de la población trae serias implicaciones para el país. Las profundas modificaciones en la familia colombiana plantean retos en todos los campos sociales. Los cambios demográficos y epidemiológicos (estructura y nivel de morbimortalidad) requieren un análisis profundo, y no deben aceptarse sin reparo las explicaciones fáciles que con frecuencia se proponen desde enfoques económicos "desarrollistas".

Palabras clave: Colombia, demografía, epidemiología, crecimiento demográfico, dinámica de población, mortalidad

Demographic and epidemiologic changes in Colombia during the 20th. century: facts and explanations

Introduction. Research, education, organization and administration activities in health need an updated panoramic view of demographic and epidemiologic changes and tendencies.

Objectives. To describe the main changes in demography and epidemiology during the $20^{\text {th }}$ century in Colombia and to comment on the causative models used by some authors.

Materials and methods. A descriptive and longitudinal study. Second hand information from various sources was used. The final section of the review includes a discussion on the interpretation of data given by the original authors.

Results. In 1905-2005, population increased from 4.737.588 inhabitants to $48.864,013$. The age distribution of the population showed dramatic changes: the true pyramid, as seen in 1951, changed into a distorted figure (no apparent differences between 0 and 14 years of age). Both children and youngsters lost representation on age structure, while adult and older individuals gain representation. During 1905-1938, the birth rate was $43 \%$ and by the end of 2005 it will be $22 \%$. Mortality dropped a $75 \%$, falling from $23 \%$ in $1905-1912$ to $6 \%$ in $1885-1993$, but it rose 
a $33 \%$ after 1993 , and will reach $8,3 \%$ in 2010 . In 1938 , the urban population was $31 \%$ and in $2002,72 \%$. Mortality discriminated by cause changed in a significant manner during the second half of the $20^{\text {th }}$ century. Infectious-parasitic and perinatal diseases, the main cause of death by the end of the 1960-1969 decade, lost importance on behalf of degenerative diseases, accidents and homicides which are now the most frequent.

Conclusions. Our present population density is relatively low. The demographic change has been profound but the velocity has been more important. The aging of population has serious implications for the country. These notable modifications in Colombian families raise challenges in all social fields. The demographic and epidemiological changes (structure and level of morbimortality) require a serious analysis, and easy explanations do not have to be accepted without repairs.

Keywords: Colombia, demography, epidemiology, population growth, population dynamics, mortality.

Tener claro el panorama demográfico y epidemiológico ocurrido en el siglo XX y el vigente a comienzos del siglo XXI es útil para los planificadores y administradores de salud, educación y otras áreas, así como para quienes se dedican a la prestación de servicios en esos campos (hospitales, entidades de educación, instituciones de atención a grupos específicos como preescolares y ancianos, por ejemplo); también las autoridades (ejecutivas, legislativas, judiciales) deben conocer sobre quienes actúan. Presentar ese panorama e invitar a profundizar en su conocimiento es la justificación principal del artículo.

El cuerpo de este escrito consta de cuatro partes: 1) tamaño, estructura y ritmo demográficos en Colombia; 2) ritmo de crecimiento (dinámica) de la población; 3) distribución espacial de la población, y 4) causas de muerte por sexo y edad. Por razones de espacio, no se entra a explicar el origen o determinación de los cambios en las tendencias demográfico-epidemiológicas, pero se reconoce que ello es fundamental.

El objetivo fue describir los principales cambios demográficos y epidemiológicos sucedidos en Colombia en el siglo XX, junto con las proyecciones a corto plazo.

\section{Correspondencia}

Jaime Carmona-Fonseca

Facultad de Medicina

Grupo Malaria

Universidad de Antioquia

jaimecarmonaf@hotmail.com

Recibido: 11/02/05; aceptado: 04/08/05

\section{Materiales y métodos}

El diseño o clase de estudio corresponde a uno teórico, descriptivo, que describe la evolución en el largo plazo temporal (tendencia) a partir de información existente, procedente de varias fuentes, tanto gubernamentales como de otra índole.

Para las descripciones y análisis efectuados se trabajó casi siempre con la totalidad de la población de Colombia, es decir, se usaron datos de censos; las excepciones a lo anterior corresponden a estudios (encuestas) realizados sobre muestras representativas de la población del país o de grupos específicos (mujeres en edad reproductiva, adolescentes, etc.), lo cual se indica clara y oportunamente cada vez que sucede.

La población de referencia a la que se pretende aplicar los resultados y las conclusiones corresponde a la población colombiana en los diferentes momentos abordados.

Para alcanzar el objetivo previsto y cada uno de los elementos implicados (tamaño, estructura y ritmo demográficos; ritmo de crecimiento de la población; distribución espacial de la población; causas de muerte por sexo y edad) se buscó en forma privilegiada la información oficial colombiana, procedente del Departamento Administrativo Nacional de Estadística (DANE), bien fuese publicada por esta institución como autor o por funcionarios suyos; en segundo lugar, se seleccionó la información no oficial pero basada en los datos oficiales, así como la información de origen privado que se refiere a la población del país o de grupos específicos. También se usaron 
datos y opiniones de otros investigadores en demografía y epidemiología.

Las fuentes principales de datos fueron las publicaciones del DANE en su página de internet (1) y en la serie de nueve documentos titulada Estudios censales (Colombia: proyecciones quinquenales de población por sexo y edad, 19502050; Colombia: proyecciones departamentales de población por sexo y edad, 1990-2015; la fecundidad en Colombia según el censo de 1993. Estimaciones departamentales y municipales; Colombia: proyecciones anuales de población por sexo y edad, 1985-2015; Colombia: estimaciones departamentales de mortalidad infantil 1985-1993. Perspectivas para mediano plazo 1995-2005; Colombia: tablas abreviadas de mortalidad por sexo para fechas censales y estimaciones quinquenales 1995-2005; Colombia: proyecciones municipales de población por área, 1995-2005; La mortalidad infantil en Colombia según el censo de 1993. Estimaciones departamentales y municipales; la familia colombiana en el fin de siglo) (2). Así mismo se cuenta con los estudios de Banguero y Castellar (La población de Colombia 1938-2025. Una visión retrospectiva y prospectiva para el país, los departamentos y sus municipios) (3), del extinto Ministerio de Salud (La salud en Colombia. Tomo I, 1990) (4), de la Organización Panamericana de la Salud, OPS (La salud en las Américas, 1998) (5), de Flórez (Las transformaciones sociodemográficas en Colombia durante el siglo XX) (6), de Pabón 1993 (La mortalidad en Colombia, 1953-1991. Frecuencias por edad y sexo. Causas de defunción) (7), de Franco (El quinto: no matar) (8), de Franco y Forero (Salud y paz en un país en guerra: Colombia, año 2002) (9) y de varios estudios previos del autor de este artículo (10-13).

Mediante el uso de palabras claves o descriptores se hizo búsqueda de la literatura demográfica y epidemiológica de Colombia existente en varias bases de datos del área de la salud, como son Lilacs (Literatura Latinoamericana y del Caribe en Ciencias de la Salud http://bases.bireme.br/cgibin/wxislind.exe/iah/online/? IsisScript=iah/ iah. $x i s \& b a s e=L I L A C S \& l a n g=e$ ), SciELO (Public Health http://www.scielosp.org) y Medline (Literatura Internacional en Ciencias de la Salud http://www.ncbi.nlm.nih.gov/entrez/query.fcgi). Se usó la palabra clave "Colombia" combinada con estas otras: "demografía" (demography), "epidemiología" (epidemiology), "mortalidad" (mortality), "estructura de la población" (population structure). También se buscó la información disponible en revistas de páginas de internet, como Free Medical Journals (http://www.freemedical journals.com/) e Intermedicina (http:// www.intermedicina.com/Revfree.htm). Los artículos pertinentes hallados en estas fuentes fueron muy escasos.

Es conveniente anotar que, en Colombia, la historia institucional de estadísticas se remonta a 1906, cuando se creó la Dirección General de Estadísticas, adscrita al Ministerio de Hacienda, y convertida en 1923 en la Dirección General de Estadística, que desde 1935 tuvo como misión "recolectar, procesar y producir la totalidad de las cifras oficiales del país" (14). En 1953 se creó el Departamento Administrativo Nacional de Estadística, DANE, como entidad independiente, y en 1968 se adscribió a la presidencia de la República y se la encargó de las cuentas nacionales del país (14).

En el país son claras "las reconocidas deficiencias de los registros de población o la falta de los mismos en varios períodos de nuestra historia" (15); estas imperfecciones no impiden encarar la descripción y el análisis demográficoepidemiológico "con amplitud y coherencia aceptables" (15), pero sí explican que deba pasarse una y otra vez de una fuente a otra para tratar de construir el panorama total. Este cambio de fuentes implica, casi siempre, cambio de datos, sobre todo cuando se trabaja con proyecciones, pues los procedimientos usados para ajustar los censos son variados y lo mismo sucede con los empleados para hacer proyecciones.

La demografía estudia el tamaño y la estructura de la población por sexo, edad, estado civil y otras características, así como el ritmo o velocidad (dinámica) en que ocurren cambios en la misma y los procesos que determinan tales modificaciones $(16,17)$.

Los estudios demográficos sobre salud y mortalidad se confunden frecuentemente con los 
Cuadro 1. Población y parámetros demográficos básicos, Colombia, 1905-2005 (tasas por mil; EVm ${ }^{1}$ en años).

\begin{tabular}{rrrrrrrrrr}
\hline Año & Población $^{2}$ & Lapso $^{3}$ & $\mathbf{C T}$ & $\mathbf{N}$ & $\mathbf{M}$ & $\mathbf{M I}$ & $\mathbf{E V m}$ & $\mathbf{M C}-\mathbf{C}$ & $\mathbf{U}(\%)$ \\
\hline 1905 & 4.737 .588 & & & & & & & & \\
1912 & 5.386 .503 & $1905-12$ & 19,10 & 42,51 & 23,41 & - & - & - & - \\
1918 & 6.120 .049 & $1912-18$ & 19,31 & 42,80 & 23,49 & - & - & - & - \\
1938 & 8.701 .816 & $1918-38$ & 20,01 & 42,83 & 22,82 & 212,9 & 40,0 & - & 29,1 \\
1951 & 11.548 .172 & $1938-51$ & 24,10 & 44,10 & 20,00 & 123,3 & 45,5 & 12,0 & 38,7 \\
1964 & 17.484 .508 & $1951-64$ & 29,80 & 45,47 & 13,17 & 85,5 & 53,2 & 22,0 & 52,0 \\
1973 & 22.862 .118 & $1964-73$ & 28,55 & 41,07 & 9,88 & 66,9 & 58,6 & 30,0 & 59,3 \\
1985 & 30.062 .200 & $1973-85$ & 23,32 & 32,64 & 7,41 & 53,3 & 63,1 & 15,0 & 65,3 \\
1990 & 33.321 .758 & $1985-93$ & 21,17 & 27,51 & 6,34 & 46,5 & 64,7 & 12,3 & 69,1 \\
1995 & 36.565 .466 & $1990-95$ & 20,20 & 25,70 & 7,10 & 44,3 & 65,3 & 12,0 & 69,9 \\
2000 & 39.762 .707 & $1995-00$ & 18,10 & 23,60 & 7,40 & 40,5 & 66,0 & 10,0 & 71,7 \\
2005 & 42.887 .162 & $2000-05$ & 16,20 & 22,10 & 7,80 & 37,0 & 66,6 & 8,0 & 73,2 \\
2010 & 45.916 .802 & $2005-10$ & 14,60 & 20,50 & 8,30 & 34,0 & 67,0 & 7,0 & 74,5 \\
2015 & 48.834 .013 & $2010-15$ & 13,00 & 19,40 & 8,90 & 30,9 & 67,4 & 7,0 & 75,7 \\
2020 & 51.625 .191 & $2015-20$ & 11,70 & 18,50 & 9,60 & 28,3 & 67,7 & 5,5 & 76,6 \\
2025 & 54.280 .617 & $2020-25$ & 10,40 & 17,60 & 10,30 & 25,8 & 67,9 & 5,0 & 77,5 \\
\hline
\end{tabular}

La población ha crecido en cifras absolutas entre 1905 y el presente, y según las proyecciones, así seguirá, pero la velocidad de crecimiento, medida por la tasa de crecimiento total, muestra que los ritmos han variado en diferentes lapsos. La tasa de natalidad disminuye desde 1964, mientras las tasas de mortalidad general y mortalidad infantil decrecen desde el inicio del siglo 20. La esperanza de vida aumenta desde que se tienen datos, tal como lo refleja inclusive la de los hombres, aunque ellos tienen menor esperanza vital que las mujeres. El porcentaje de migración del campo a la ciudad ha variado en el tiempo y es decreciente desde hace más de treinta años, a pesar de lo cual, el porcentaje de habitantes que reside en áreas urbanas es creciente desde por lo menos 1938.

1 CT: tasa de crecimiento total, N: tasa bruta de natalidad, M: tasa bruta de mortalidad, MI: tasa de mortalidad infantil, EVm: esperanza de vida masculina, MC-C: migración campo-ciudad, U (\%): porcentaje de población urbana.

2 Datos de población procedentes de dos fuentes que usan diferentes formas de ajuste para las proyecciones intercensales; en general, se usan los datos de Flórez (6) hasta 1985 (1985-93) y los de Banguero y Castellar (3) de 1990 en adelante. Los valores de Flórez son, en general, más pequeños que los de la otra fuente.

3 Todas las tasas son el promedio del lapso.

estudios epidemiológicos sobre el tema; estos últimos, a diferencia de los primeros, abordan el estudio de los factores de riesgo y su medición, además de analizar la distribución de la enfermedad y la muerte prematura (16).

\section{Resultados}

Tamaño, estructura y ritmo demográficos en Colombia

El tamaño de la población y la estructura por sexo, edad y etnia

La población. En 1770 había 806.209 habitantes, en 1810 eran $1 ' 400.000$, en 1825 eran 1 '223.598, en 1851 eran 2'243.054, en 1871 eran 2'951.111. Entre 1770 y 1871 (en 101 años) la población se triplicó y en los 34 años entre 1871 y 1905 se duplicó, pues subió a 4'143.632 $(18,19)$.

Entre 1905 y 2005 (en 100 años), la población de Colombia se multiplicó por 9 , al pasar de 4'737.588 habitantes a 42' 887.162 en 2005 , y proyecciones de 45'916.812 en 2010, 48'864.013 en 2015 y $54 ' 208.617$ en $2025(3,6)$ (cuadro 1, figura 1). Según las proyecciones del DANE, consultadas en noviembre de 2004, los datos son algo diferentes a los anteriores, pues indican 42'321.386 de habitantes en 2000, 46'039.144 en 2005, 49'665.341 en 2010 y 53'182.961 en 2015 (1); se espera que parte de estas diferencias se aclaren con el próximo censo (el último fue en 1993).

Las poblaciones de hombres y mujeres. La población de hombres siempre ha sido $0,5 \%$ a $1,5 \%$ menor que la de mujeres. El número de hombres por cada cien mujeres fluctuará entre 97,6 y 98,7 de 1985 a 2015, con una mediana de $97,9(1)$.

Indígenas y negros. La población indígena y negra representaría el 0,32\% de la población colombiana de 36 millones de habitantes según el censo de 


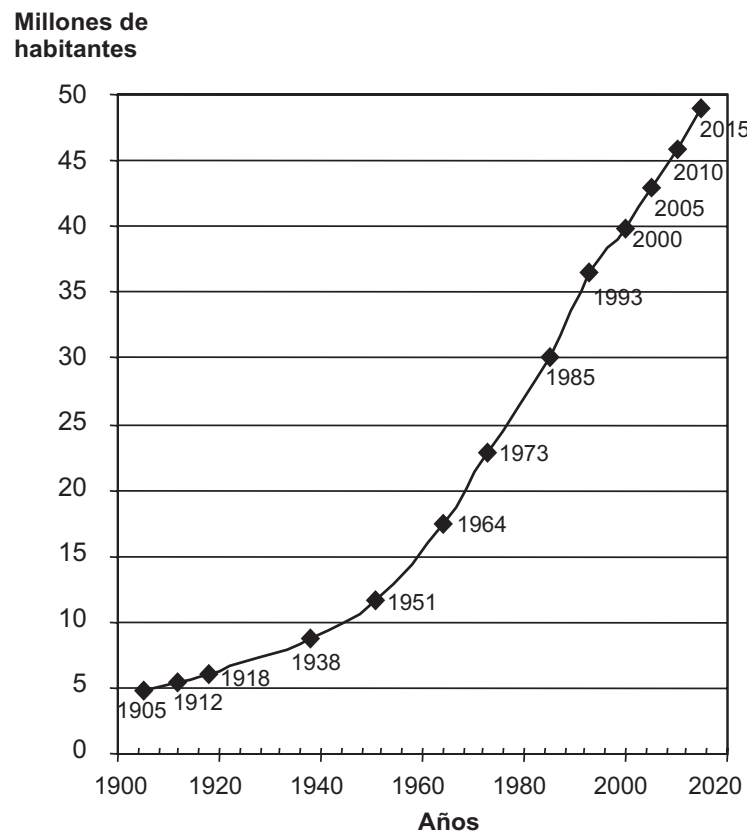

Con base en datos de: Banguero y Castellar; Flórez

Figura 1. Población (millones) de Colombia, 1905-2005.
1993, cuando el DANE registró en el ítem de "población indígena y negra" un total de 1'105.499 personas, de las cuales 574.282 eran indígenas de las 81 etnias que viven en el territorio colombiano y 603.152, negros (20).

La estructura por edad. De acuerdo con la edad, la distribución de la población colombiana durante el siglo XX ha presentado cambios profundos. De una clásica y verdadera pirámide, presente en 1905 y 1951, se pasa en 1985 a una figura deformada, a una especie de pirámide trunca, en el sentido de que entre su base (cero años) y los 14 años no existe diferencia apreciable. Para 2015 se espera que entre la base y los 29 años no haya diferencia importante en la frecuencia por grupo de edad (figura 2). Es claro que los niños y jóvenes (menores de 15 años) han perdido mucho peso en la estructura por edad, mientras que los adultos y ancianos han ganado mucha presencia. En otras palabras, en los 100 años transcurridos entre 1905 y 2005, la población colombiana muestra un significativo proceso de envejecimiento, en el que

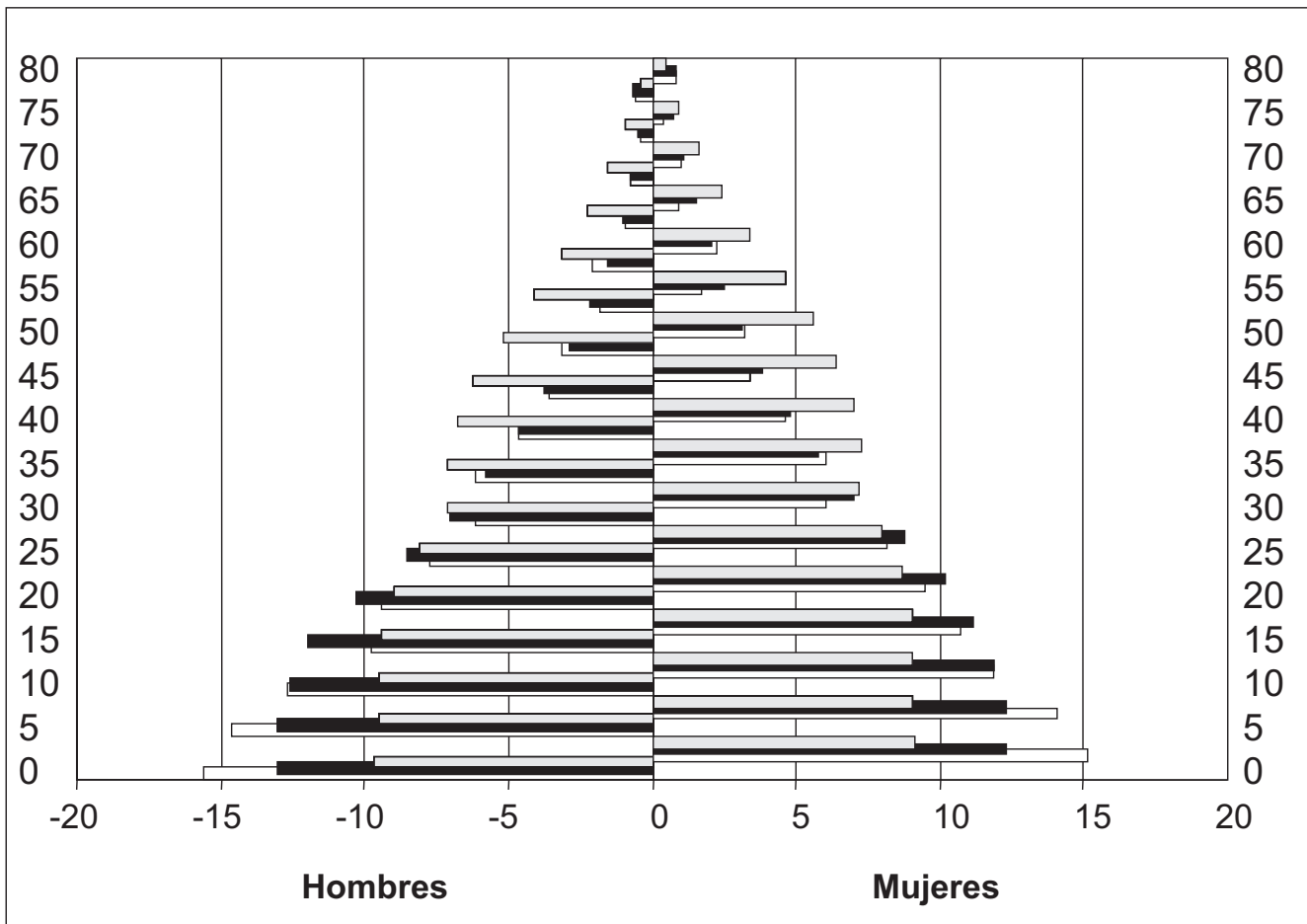

1905: blanco, 1985: negro, 2015: gris

Con base en datos de Banguero y Castellar; Flórez

Figura 2. Pirámides de población. Colombia, 1905, 1985 y 2005. 

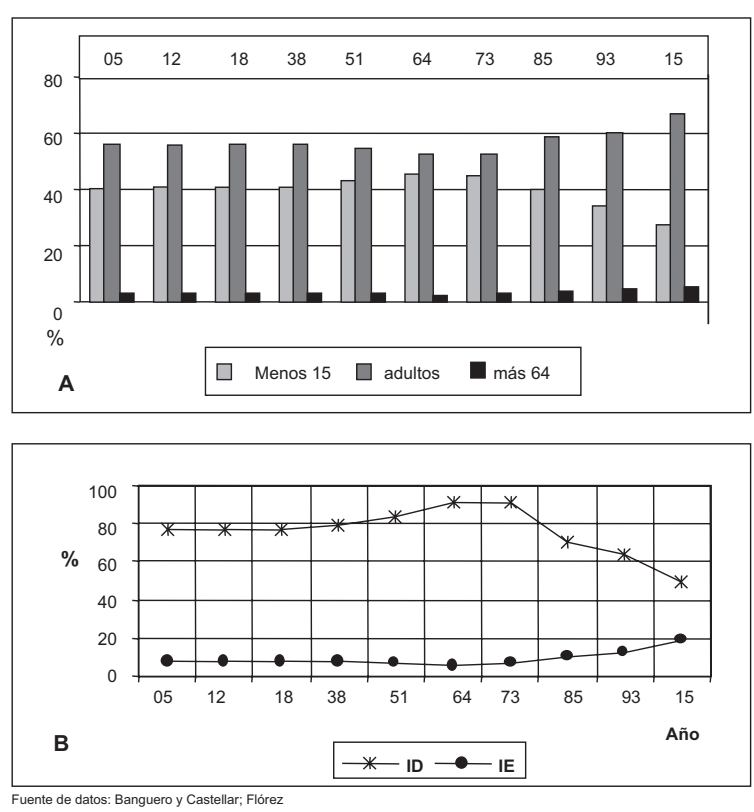

Figura 3. Población de Colombia, 1905-2015.

A. Población por grandes grupos de edad

B. Índices de dependencia (D) y de envejecimiento (E)

los adultos ( 15 a 64 años) se han convertido en el grupo francamente dominante, a expensas de los niños y adolescentes (0 a 14 años) (figura 3A). Este envejecimiento se aprecia en forma nítida al comparar la edad mediana de la población en diferentes fechas: en 1950 era de 18,7 años (15), de 1985 a 2015 ha sido de 24,0 años (1) y en 2025 será de 31 años (15).

El índice de dependencia mide cuántos jóvenes y viejos hay por cada adulto (menores de $15+$ mayores de 64/15 a 64 años, expresado como fracción o porcentaje). En 1905 ese índice era 0,77 (de un adulto dependían 0,77 no adultos); en 1964 alcanzó el máximo de 0,92; en 1993 cayó a 0,63 y en 2005 será de 0,60 (figura $3 B$ )(3,6). El índice de envejecimiento indica cuántos ancianos existen por cada menor de 15 años (mayores de $64 /$ menores de 15 , expresado como fracción o porcentaje), el cual fue casi estable entre 1905 y 1938 (alrededor de 7,5\%), y descendió hasta 1964, pasando de $7,28 \%$ en 1938 a 5,47\% en 1964; desde entonces ha venido subiendo y llegó a $12,34 \%$ en 1993 (6) y en 2015 será de 19,03\% (calculado con datos de (6)); así, por cada 100 menores de 15 años, teníamos en 1993 más de 12 ancianos, cuando en 1964 eran 5,47 viejos (figura 3B).

\section{La población estudiantil}

Los diferentes grupos en edad de estudio (aunque no necesariamente estén estudiando) se vienen reduciendo desde fines del decenio de 1960 y seguirán en reducción en el futuro inmediato, excepto el grupo en edad universitaria, que se mantendrá relativamente estable. Los cambios entre 1938 y 2005 han sido los sifuientes (figura 4) (3): población preescolar (5 a 7 años), que en 1938 y 1951 representó $8,77 \%$ y $13,29 \%$ del total, respectivamente; en los demás censos se aprecia una tendencia francamente decreciente y en 1985 ese grupo constituye 7,69\%; en 1995 se estima en $6,85 \%$, en 2000 tiene $6,69 \%$ y para 2005 se espera que represente $6,33 \%$; las proyecciones hasta el 2025 señalan una tendencia decreciente. Población escolar de primaria (6 a 12 años), la cual crece porcentualmente entre 1938 y 1973, pasando de $16,38 \%$ a $21,29 \%$; desde entonces tiene tendencia a caer, situándose en 1995 en $14,98 \%$ y en 2005 será de 12,52\%. Población escolar de secundaria (13 a 18 años), que fue bastante estable entre 1938 y 1990, pues su participación oscila entre el mínimo de $12,45 \%$ en 1951 y el máximo de $14,22 \%$ en 1985 ; se redujo a $12,28 \%$ en 1995 , es de $11,56 \%$ en 2005 y será de $10,10 \%$ en 2025 . Población en edad universitaria ( 19 a 25 años), la cual decreció entre 1938 y 1973 , pasando de $13,65 \%$ a $11,44 \%$; en 1985 representó el $15,12 \%$ y volvió a disminuir hasta el presente (12,99\% en 2000), esperándose

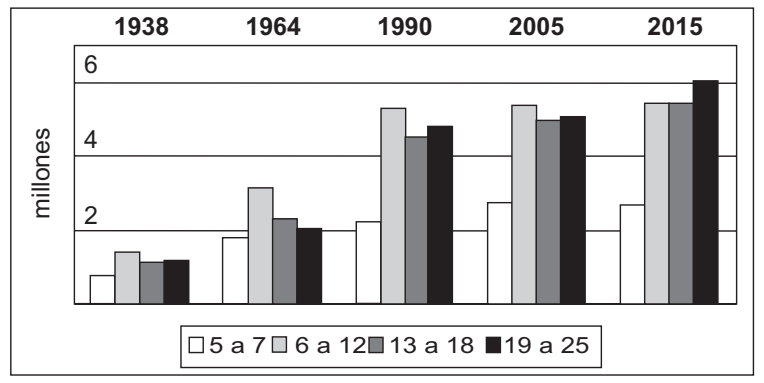

Con base en datos: Banguero y Castellar

Figura 4. Participación en la población total de los grupos en edad de estudio. Colombia, 1938-2015. 
$11,87 \%$ para 2005 y manteniéndose en alrededor de $12 \%$ en las proyecciones hasta 2025 .

\section{La población laboral}

En cuanto a la población laboral, "la disminución de la fecundidad afecta, con un rezago de 15 años, la oferta de trabajo, en la medida en que ingresan a la población en edad de trabajar cohortes cada vez más reducidas. Sin embargo, este efecto positivo sobre el mercado laboral es compensado en parte por el aumento de la participación de la mujer en el mercado laboral en la medida en que reduce su tamaño de familia. Hay tendencia importante al crecimiento de la oferta laboral en Colombia a partir de 1973 para luego estabilizarse en el próximo siglo (el XXI) en la medida en que se estabiliza la tasa de participación de la mujer en el mercado laboral" (3).

El gran grupo de población con edades entre $15 y$ 59 años, que es población en edad de trabajar, se comporta igual al grupo de 15 a 64 años, del cual ya se dijo que se ha convertido en el grupo francamente dominante, a expensas de la participación de los niños y adolescentes $(0$ a 14 años). El grupo de 15 a 59 años representó el $52,97 \%$ en 1938 y cayó a 50,74\% en 1973, subió a $57,13 \%$ en 1985 y, desde entonces siguió aumentando hasta llegar a $61,24 \%$ en 2000 y ascenderá a 63,10\% en 2025 (3). En resumen, la fuerza laboral disponible crece y crecerá en Colombia en los próximos 20 años.

\section{El ritmo de crecimiento o dinámica de población}

\section{La natalidad y la fecundidad}

La población genera nacimientos y muertes. La cantidad de nacimientos puede expresarse en términos de individuo, en el sentido de los hijos que tiene una mujer, y ello tiene que ver con la fecundidad, o en términos colectivos, en el sentido de la cantidad de niños nacidos vivos por cada mil habitantes (hombres y mujeres) en cierto período, que hace referencia a la natalidad. La fecundidad se refiere a los hijos que tenga una mujer, y su base es la fertilidad, o sea, la capacidad (potencialidad) de tenerlos. La natalidad se ocupa del hecho de que la sociedad (hombres y muejres) tenga nuevos hijos, nuevos miembros. Hay diversas medidas de la natalidad y la fecundidad que se complementan entre si para dar cuenta de los cambios cruciales que se derivan del hecho de nacer ${ }^{1}$.

En Colombia, la tasa bruta de natalidad (TBN) permanece alta y estable durante los primeros treinta años del siglo $\mathrm{XX}$, cuando la mortalidad también era alta y constante. Entre 1905 y 1938 , la TBN estaba alrededor de 43 por mil, subió a 44 en 1951, alcanzó 46 por mil en 1964, cayó a 41 por mil en 1973, luego a 33 por mil en 1985, a 28 por mil en 1993 y se supone en 22 por mil en 2005 (3). En los 60 años transcurridos entre 1905 y 1964 , la TBN creció $7 \%$ (pasó de 42,51 por mil a 45,47 por mil) (6), pero en apenas 30 años (1963 a 1993) cayó $40 \%$ (de 45,47 pasó a 27,51 por mil); si en 2005 llega a estar en 22 por mil, significará una reducción de $20 \%$ en apenas 5 años (cuadro 1, figura 5).

Antes de 1940, la natalidad y la mortalidad eran "altas", pero la población creció poco y lentamente. La natalidad (TBN) creció hasta mediados del decenio de 1960, mientras que la mortalidad decreció en forma acentuada desde fines del decenio de 1930, de tal forma que hay una brecha entre ambos fenómenos de unos veinticinco o más años, brecha que produjo un apreciable y rápido crecimiento de la población, reflejado en la tasa de crecimiento total, que se aceleró de manera importante entre 1938 y 1985, año este último cuando vuelve a su nivel de 1938. Después de 1985 , la natalidad y la mortalidad son "bajas" y, de nuevo, creció poco y lentamente.

La radical reducción de la natalidad se relaciona muy bien con una similar disminución de la fecundidad. La tasa total de fecundidad (TTF) mantuvo niveles altos hasta el decenio de 1960; esa tasa pasó de 7,04 hijos por mujer en 1951 a menos 3,30 en 1985 y se espera que sea de 2,7 para finales de 2005 (figura 6) (3).

\footnotetext{
La tasa bruta de natalidad (TBN) es el número de nacimientos vivos en cierto período, generalmente un año, por cada mil habitantes (hombres y mujeres) que residen en un lugar. La tasa general de fecundidad (TGF) es el número de nacimientos vivos por cada mil mujeres de 15 a 44 años de edad en un año y en un área determinada. Hay muchas otras medidas, como tasa de fecundidad específica por edad (TFE), tasa total de fecundidad (TTF), tasa bruta de reproducción (TBR), tasa de fecunidad específica por orden de nacimiento (TFO), tasa de fecunidad marital (TFM). Consúltese: Rico Velasco J. Demografía social y salud pública. Cali: Universidad del Valle; 1993. p. 81-98.
} 

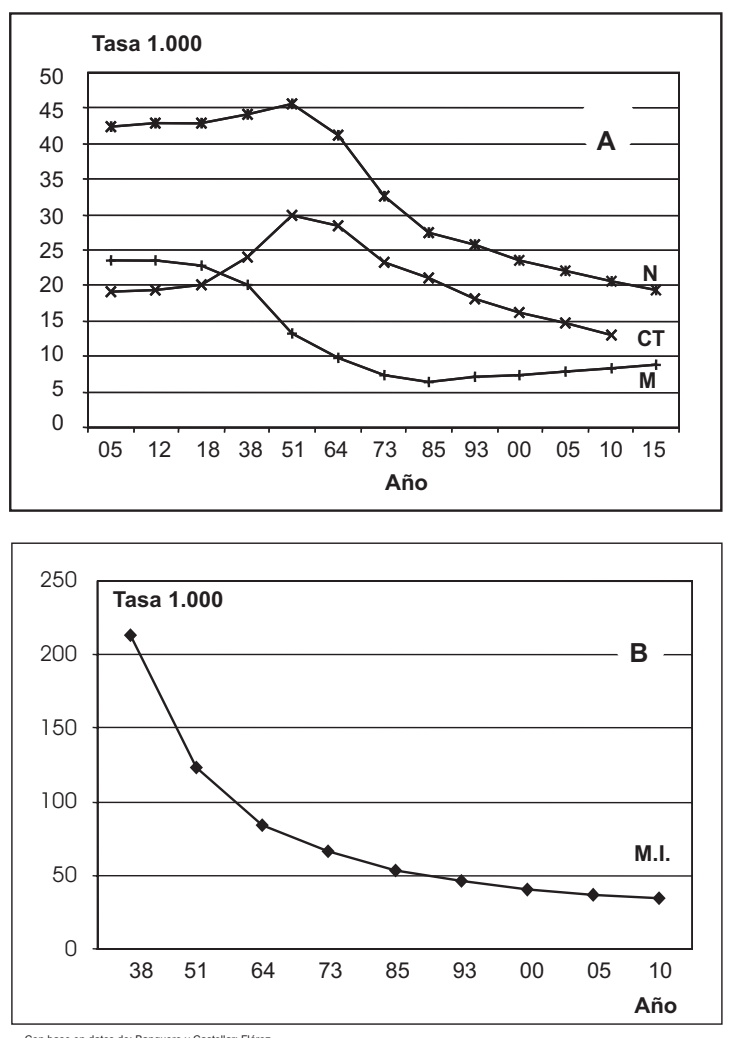

Figura 5. Tendencias de las tasas de natalidad, mortalidad, crecimiento total (parte A) y de mortalidad infantil (parte B). Colombia, fecha 1-2. $\mathrm{N}$ : natalidad

$\mathrm{CT}$ : crecimiento total M: mortalidad

MI: mortalidad infantil

La fecundidad y sus determinantes: nupcialidad y anticoncepción

"En Colombia, en 1964, etapa pre-transicional, sólo un $27 \%$ de las mujeres en edad fértil y en unión usaban métodos anticonceptivos. En 1995, etapa avanzada de la transición (demográfica), un $72 \%$ de ese mismo grupo de mujeres usaba métodos. (...) El uso de anticonceptivos aumentó de 15\% a $67 \%$ entre las mujeres unidas de la zona rural, entre 1969 y 1995. (...) En la zona urbana, el aumento (...) ha sido menos marcado: la proporción de mujeres unidas que usan planificación familiar pasó de $43 \%$ a $75 \%$ en el mismo período de 26 años" (6). Entre 1985 y 1999, las jóvenes solteras de Colombia, como las de

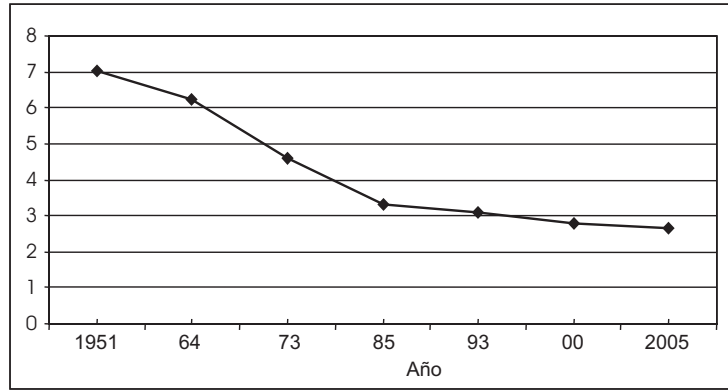

Con base en datos de: Banguero y Castellar; Flórez

Figura 6. Tasa total de fecundidad (promedio de hijos por mujer). Colombia, 1951-2005

Perú, fueron sexualmente más activas a edad cada vez menor y, al tiempo, hubo un mayor uso de métodos anticonceptivos, en especial el condón; también sucedió una abrupta reducción de los embarazos prematrimoniales informados (21). Según un estudio reciente sobre esterilización femenina en Brasil, Colombia, Perú y República Dominicana, basado en datos de 1995-1996, en los cuatro países hay un patrón consistente que señala una probabilidad creciente de esterilización a medida que aumenta el nivel educativo (22).

\section{Cambios en la familia}

En Colombia, en la segunda mitad del siglo XX, ganó importancia la unión consensual con respecto a la legal. Estas uniones consensuales han ganado más participación en el grupo de menor nivel educativo (6). Durante 1980 a 2000, la cohabitación no matrimonial reemplazó al matrimonio y entre la gente más joven llegó a ser la forma de unión más aceptada (23). Los datos de la investigación nacional de demografía y salud de 1995 indicaron que las proporciones de familias nucleares y compuestas habían declinado, mientras que aumentaron las familias incompletas encabezadas por una mujer, los hogares de un padre y los hogares nucleares de parejas sin hijos; en cifras, esta fue la situación: $58 \%$, familias nucleares; $30 \%$, extensas (nuclear y otros familiares); $5,5 \%$, compuestas; $6,5 \%$, hogares unipersonales (23).

\section{La mortalidad general}

La mortalidad en la población total y por todas las causas se llama mortalidad general y se mide con 
la tasa bruta de mortalidad (TBM), que cayó $75 \%$ durante el siglo XX y pasó de 23 por mil en el periodo de 1905 a 1912 a 6 por mil en el de 1985 a 1993 , pero que subió a $33 \%$ después de 1993 , al llegar a 7,4, a 7,8 y a 8,3 por mil en 2000,2005 y 2010 , respectivamente, y con tendencia creciente en adelante debido al envejecimiento de la población (cuadro 1 y figura 5) $(3,6)$. La tendencia a rebajar fue fuerte hasta 1978, pero de ahí en adelante la situación fue bastante estable hasta 1991 (7).

La mortalidad general por sexo/sexo entre 1953 y 1991 en Colombia siempre fue mayor para los hombres que para las mujeres y ambos grupos presentaron una tendencia francamente decreciente (7); sin embargo, la tendencia a disminuir fue muy clara entre 1953 y 1978 para ambos grupos, pero después, mientras el riesgo para las mujeres continuó reduciéndose, la probabilidad de muerte para los hombres empezó a crecer (7) como lo indica la figura 7. La diferencia entre las tasas de mortalidad masculina y femenina en 1978 fue alrededor de 1,2 por mil (5,5 frente a 4,4 por mil, respectivamente), pero en 1991 la diferencia fue de 2,3 por mil (6,0 y 3,7 por mil, en su orden), lo que implica que la diferencia se duplicó en 14 años (7). En la sección titulada Los patrones de mortalidad se indica lo relacionado con las causas específicas de muerte por sexo y edad y se presentan más datos y análisis relacionados con la mortalidad entre hombres y mujeres.

\section{La mortalidad infantil}

La mortalidad infantil mide la probabilidad de morir en el primer año de vida. "Desde la segunda mitad de la década de los treinta, el país ha experimentado un descenso notable de este indicador. Mientras en los primeros treinta años de este siglo se tuvo una mortalidad infantil de alrededor de 186 defunciones por mil nacidos vivos, hacia finales de siglo se reduce en más del $80 \%$, a niveles cercanos a los 35 por mil" (figura 5) (6). La excesiva mortalidad infantil masculina ha sido constante en este tiempo (1905-1995). La mortalidad general desciendió desde fines del decenio de 1930, y aunque la mortalidad infantil también lo hizo por esta época, su nivel fue muy alto (superior a 200 muertes por mil nacidos vivos), de forma tal que apenas a comienzos del decenio de 1960 empezó a caer a valores notoriamente menores a los precedentes (cuadro 1).

A finales del siglo $X X$, la mortalidad infantil colombiana era inferior al promedio de Latinoamérica, que se sitúa en 49 por mil, pero un valor de 35 por mil todavía es relativamente alto, como quiera que su nivel entre 1990 y 1995 superó en más de cuatro veces al de Norteamérica (8 por mil) y que 15 de 30 países latinoamericanos mostraban niveles muy inferiores a Colombia, como Panamá (21 por mil), Costa Rica (17 por mil) y Cuba (13 por mil) (6).

La mortalidad infantil en Colombia es menor en las zonas urbanas que en las rurales. En 1970, era $40 \%$ mayor la observada en las zonas rurales: 89,4 por mil frente a 63,9 por mil; en 1989 se mantenía esta diferencia (37\% más la rural): 50,4 contra 36,9 por mil (6). Esta diferencia fue estable en todo el lapso de 1970 a 1989.

\section{El efecto de los cambios en natalidad y mortalidad sobre la distribución por edad}

El paso de niveles altos a bajos de natalidad y de mortalidad tiene un efecto demográfico sobre la estructura por edad de la población: tiende a envejecerla. En efecto, a comienzos del siglo XX, cuando las tasas de natalidad y mortalidad eran altas y estables, alrededor de 43 y 22 por mil, respectivamente (figura 4), la población colombiana estaba integrada por $40 \%$ de menores de 15 años y $60 \%$ de 15 y más años, mientras que en 1993 dichas tasas eran bajas y decrecientes, alrededor de 27 y 6 por mil, respectivamente, asociadas a una población menor de 15 años que representaba 35\% del total, en un claro proceso de envejecimiento, como lo revelan las deformidades en las pirámides de población.

\section{Un punto extremo de comparación}

Lo dicho hasta ahora se refiere a datos promedio para Colombia, los cuales dicen mucho y, a la vez ocultan otro tanto, por cuanto las enormes diferencias regionales y locales quedan sin revelar. Como simple ilustración, uso los datos de una investigación en poblaciones indígenas 
colombianas, que son ciertamente un extremo muy alejado del resto de la Colombia "moderna", entendido este concepto en la forma como Agudelo lo explica (15).

El objetivo del trabajo fue obtener indicadores demográficos para comunidades indígenas colombianas, localizadas en tres grandes regiones del país: la del Caribe (etnias wayú y arhuaco), la amazónica (16 etnias, con predominio de los cubeos, desanos, puinaves y tukanos), y la andina (etnias coyaima, páez, emberá). Se analizaron las variables demográficas de una encuesta sobre conocimientos, actitudes y prácticas, realizada entre 1993 y 1994, con una muestra de 11.522 indígenas. Los resultados fueron: $45 \%$ de la población era menor de 15 años; la tasa global de fecundidad era de 6,5 hijos por mujer y la tasa de mortalidad infantil en 1990 era de 63,3 por 1000 nacidos vivos. La esperanza de vida al nacer fue de 57,8 años para mujeres y de 55,4 años para hombres. La conclusión es que los indicadores difieren sustancialmente del promedio nacional (24).

Hay apreciables diferencias en la situación y los cambios demográficos y epidemiológicos entre, por ejemplo, Quindío y Antioquia, entre ésta y Chocó o Sucre, entre todos estos lugares y Bogotá, D.C. La adecuada formulación de políticas demográficas y de salud para la población de tales sitios exige conocer esos detalles.

\section{La distribución espacial de la población}

\section{Población urbana-rural y migración rural-urbana}

La población llamada urbana no es sinónimo de población que reside en la cabecera; tampoco la población que vive en el resto del territorio de cada municipio (el todo menos el casco urbano o cabecera) es sinónimo de población rural. La ciudad mediana o grande tiene casco urbano y zona periférica (resto), que no es igual a rural, pues por ello se entiende, usualmente, la parte no urbano (fuera de la cabecera) de los pequeños pueblos. La migración rural-urbana se refiere, generalmente, al flujo de las cabeceras y del resto del territorio de los pequeños pueblos hacia las ciudades medianas y grandes. Es claro que en ese caso lo rural incluye tanto la cabecera como la periferia o resto. Esos términos (urbano, cabecera, rural, periferia, resto) deben ser explícitamente definidos.

"Una de las grandes transformaciones que ha vivido Colombia durante el siglo XX ha sido la de su urbanización: se pasó de un país rural a uno predominantemente urbano" (6). En 1938, la población que vivía en las cabeceras municipales (población urbana) era $31 \%$ del total y en 2000 era $72 \%$. Hacia 1963-1964 estuvieron en un punto de equilibrio (cada una era $50 \%$ ) (figura 8).

La velocidad o ritmo de crecimiento de la población en las cabeceras es más intensa (acelerada) que en el resto (periferia), sobre todo desde mediados del decenio de 1960 hasta hoy. Entre 1938 y 2000 la población en cabeceras pasó de 2.753 millones de personas a 28.506 sujetos $(3,6)$, es decir, un aumento de 10,35 veces (10,35\%), que equivale a un incremento promedio anual de 409.000 personas (el aumento de personas, que es de 25.753 millones, dividido por 63 años indica la diferencia entre 2000 y 1937). En cambio, en el resto del territorio (periferia), la población aumentó de 6.145 millones en 1938 a 11.257 millones en $2000(3,6)$, que implica un aumento total de 1,83 veces $(1,83 \%)$ y un incremento anual de 81.000 individuos $(1,832 / 63=0,081)$. La diferencia entre los crecimientos total y en cabecera puede deberse al efecto del crecimiento natural o a la transferencia neta de la población de localidades rurales a urbanas (de periferia a casco urbano) ${ }^{2}$. En Colombia, la fecundidad en la zona rural ha sido siempre superior a la urbana y, por ello, el crecimiento natural (natalidad menos mortalidad) rural es superior al urbano. En consecuencia, la diferencia entre los crecimientos total y en cabecera se debe fundamentalmente a la transferencia neta de población de localidades rurales a urbanas (6).

Es importante notar que "a pesar de que la población rural ha presentado tasas de crecimiento natural mayores a las de la población urbana, la migración neta ha contrarrestado su crecimiento demográfico. La población rural presenta una

\footnotetext{
2 La transferencia rural-urbana incluye la migración más la reclasificación de las localidades (6).
} 


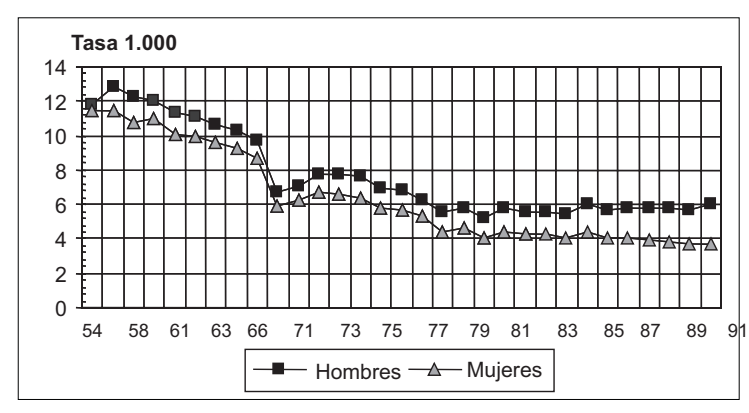

Con base en datos de Pabón

Figura 7. Tasa (por mil) de mortalidad general por sexo, Colombia, 1954-1991

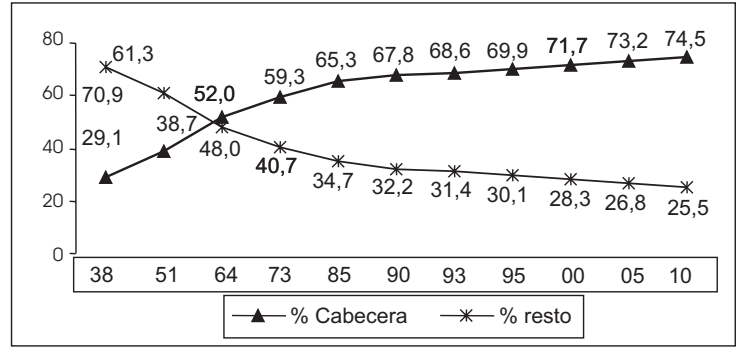

Con base en datos de: Banguero \& Castellar, Flórez para 1993

Figura 8. Población (\%) en cabeceras y fuera de ellas, Colombia, 1905-2010

disminución sistemática de su crecimiento (tasa), con una relativa estabilidad durante las últimas tres décadas del siglo" (6). Al analizar las tendencias demográficas en las zonas rurales colombianas entre 1951 y 1985, se halló una gran declinación de la fecundidad y aumento de la esperanza de vida (25).

\section{Las migraciones internacionales}

Banguero y Castellar, citando un análisis de A. López-Toro sobre migración internacional, basado en los censos de 1951 y 1985, dicen que antes de 1964 hubo un significativo proceso migratorio de colombianos hacia Venezuela, Estados Unidos de América, Panamá y Ecuador (3). Según estos mismos autores, a partir de 1985 cabía esperar que la corriente migratoria hacia esos países se invirtiera, de tal manera que a Colombia llegaran del exterior más personas de las que salían. La predicción fue formulada en 1993 y, contra los datos empíricos de la realidad cotidiana, hay que señalar que resultó totalmente fallida, pues el flujo

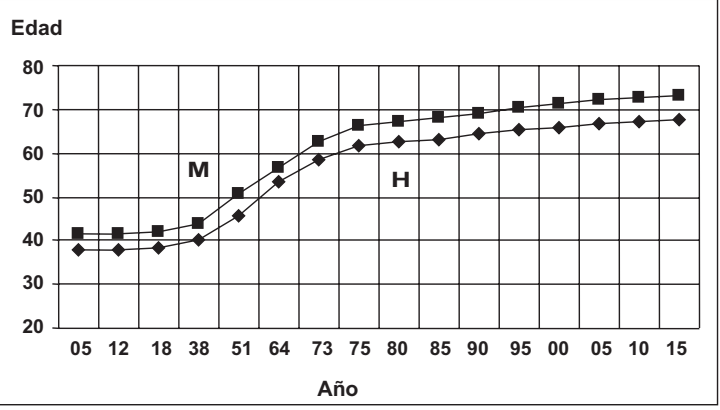

Con base en datos de Banguero \& Castellar; Flórez

Figura 9. Años de esperanza de vida al nacer, por sexo, Colombia, 1905-2015

migratorio hacia el exterior no sólo se mantuvo como antes de 1985 sino que se acentuó. A esos destinos citados antes se han sumado otros, como España y Costa Rica.

La conclusión, entonces, es que la migración internacional, al menos en la segunda mitad del siglo XX y hasta el presente, ha contribuido al decrecimiento de la población colombiana. De acuerdo con Agudelo, "en una perspectiva a largo plazo, la migración internacional no ha tenido una incidencia significativa en el crecimiento de la población" colombiana (15).

\section{Las causas de muerte por sexo y edad}

Los datos básicos de mortalidad son los que resultan del registro civil de defunción. "Los datos de mortalidad son la base para una amplia gama de indicadores de diversa complejidad. No sólo representan las herramientas para evaluar el riesgo de muerte en una población y la repercusión de las enfermedades en la salud, sino también la gravedad de las enfermedades y la sobrevivencia (sic) experimentada por la población" (26).

Entre tales indicadores, que no se desarrollarán en este escrito por cuestión de espacio y que aportan una visión diferente y complementaria a la dada por las proporciones y tasas de mortalidad, están la esperanza de vida al nacer o vida media (EVN) (figura 9) $(6,17,26)$, los cambios en la EVN debidos a causas específicas de muerte (27), años de vida saludable perdidos anualmente (Avisa o Avispa) (28), los años potenciales de vida perdidos ( APVP) (también referidos como años de vida 


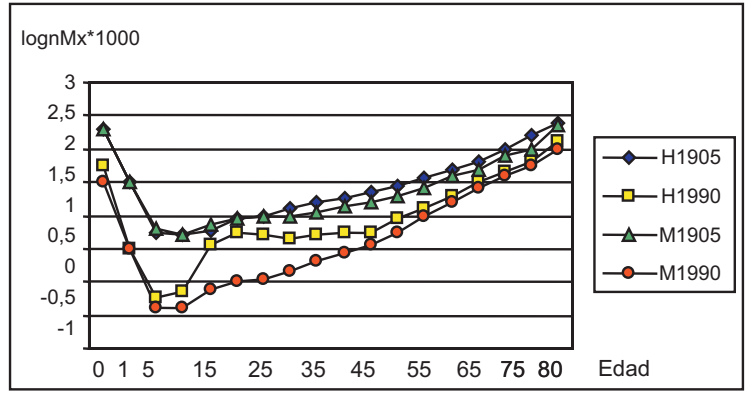

Con base en datos de Flórez

Figura 10. Patrones de mortalidad por sexo y edad, Colombia, 1905 y 1990.

potenciales perdidos, AVPP) (26), los años de esperanza de vida perdidos (AEVP) (26), los años de vida ajustados por discapacidad (AVAD) $(26,29)$, y los años de vida ajustados por calidad de vida (AVACV) (26).

\section{Los patrones de mortalidad}

Los riesgos de mortalidad son diferentes por edad y generan un patrón gráfico (forma general de la curva) en forma de $U$ (cuando el eje de las $Y$, donde se representa la tasa de mortalidad, está en escala logarítmica). "En Colombia, este típico patrón de mortalidad prácticamente no cambia, ni en su forma ni en su nivel, durante las primeras décadas del siglo XX. Es sólo a partir de finales de los treinta cuando (...se observa...) una disminución en los riesgos de mortalidad: el patrón se desplaza hacia abajo con el tiempo" (6).

El patrón de mortalidad es similar entre hombres y mujeres, pero la mortalidad en todos los grupos de edad de sexo masculino siempre es más alta que la femenina (figura 10). Un gráfico logarítmico en $U$ permite apreciar que en el primer año de vida el riesgo de morir es alto y va reduciéndose hasta los 5 a 10 años, cuando empieza a ascender en forma acelerada.

De acuerdo con Vallin, los riesgos de morir en los primeros años se deben básicamente a procesos biológicos particulares, como los riesgos del parto y perinatales, las malformaciones congénitas graves, la adaptación al ambiente; a medida que el niño se adapta, se va reduciendo la probabilidad de morir. A partir de los 5 a los 10 años (esto varía de un país a otro, de una población o subpoblación a otra) empieza a operar el proceso biológico general del envejecimiento, salvo por una protuberancia que ocurre hacia los 20 años, debida a causas no biológicas sino sociales, como son los accidentes de tránsito. "Es por ello que, dentro del marco impuesto por los procesos biológicos, la mortalidad real depende también de los comportamientos sociales y del contexto sanitario" (17). Esta descripción se observa en el caso de las curvas colombianas por sexo.

"No es posible reconstruir la participación de cada uno de los grupos de edad en la tendencia descendente de largo plazo de la mortalidad general. Sin embargo, la experiencia de dos décadas, 1970-90, es ilustrativa en este sentido" (15). Para todos los grupos se reduce el riesgo de morir (expresado en la tasa de mortalidad), mientras el aporte porcentual de los grupos en el total de muertes varía: se reduce para todos los grupos menores de 15 años y aumenta para los mayores de esa edad (cuadro 2). Estos cambios en el aporte porcentual reflejan el envejecimiento relativo de la población.

Las causas específicas de muerte: lo "atrasado" y 10 "moderno"

Las causas de mortalidad (mortalidad específica) por sexo y grupo de edad varían de esta manera (6): a) en la infancia las causas difieren poco por sexo; b) en mujeres adolescentes y adultas aumenta la mortalidad por causas relacionadas con las complicaciones de la maternidad (embarazo, parto, puerperio) y por cáncer femenino, mientras que en los hombres aumenta

Cuadro 2. Mortalidad en los grupos de edad: reducción del riesgo de muerte (tasa por mil) y variación del aporte porcentual del grupo al total de muertes. Colombia, 1970 $1990^{(1)}$.

\begin{tabular}{lll}
\hline $\begin{array}{l}\text { Edad } \\
\text { (años) }\end{array}$ & $\begin{array}{c}\text { Riesgo de muerte } \\
\text { (tasa por mil) }\end{array}$ & $\begin{array}{c}\text { Aporte a las muertes } \\
\text { (\% del total) }\end{array}$ \\
\hline$<1$ & cae de 51 a 20 & cae de 23 a 11 \\
$1-4$ & cae de 7 a 2 & cae de 12 a 4 \\
$5-14$ & cae de 1,2 a 0,6 & cae de 5 a 2 \\
$15-44$ & cae de 2,6 a 2,2 & sube de 15 a 23 \\
$45-59$ & cae de 9 a 7,3 & sube de 11 a 14 \\
60 y más & cae de 55 a 43 & sube de 34 a 46 \\
\hline
\end{tabular}

(1) Con base en datos de Agudelo (15). 
la mortalidad por causas externas, con prevalencia de los accidentes, los homicidios y los suicidios; c) en los viejos, la mortalidad específica vuelve a ser similar en los dos géneros.

Dice Flórez que en Colombia "la mortalidad por causas cambió significativamente a lo largo de la segunda mitad del siglo XX, tanto para hombres como para mujeres. Las enfermedades infecciosas, parasitarias y las perinatales, principales causas de muerte en la década de los sesentas, fueron perdiendo importancia frente a las enfermedades endógenas y a las muertes por violencia. En 1965, las tres principales causas de muerte eran las enfermedades infecciosas intestinales, infecciones respiratorias agudas y perinatales que, en conjunto, representaban alrededor del $30 \%$ de todas las defunciones. A partir de la década de los ochenta son las enfermedades endógenas de orden biológico (tumores malignos, enfermedades del corazón, isquémicas, cerebrovasculares) y las enfermedades externas causadas por el hombre (homicidios, accidentes) las que ocupan los primeros lugares como causa de defunción" (6).

El descenso acelerado de la mortalidad por enfermedades infecciosas se hace claro a partir de mediados del decenio iniciado en 1970: entre 1960 y 1973, las enfermedades infecciosas pasaron de aportar $39 \%$ a $30,5 \%$ de las muertes en el país (reducción de 22\%), mientras que entre 1974 y 1990 caen de $28 \%$ a $4 \%$ (reducción de $85 \%$ ) (10). Entre 1965 y 1991, la morbilidad por infecciones también presentó un acelerado descenso (11). La razón entre las tasas de enfermedades crónicas y las enfermedades infecciosas era de 0,52 en 1960, pero en 1990 subió a 8,95. Si bien esas enfermedades "crónicas y degenerativas" aumentaron su tasa (pasaron de 476 a 603 por cien mil, es decir, un aumento de $27 \%$ ), el cambio más notorio estuvo en la reducción de las infecciosas, que cayeron de 918 a 67 por cien mil (13), o sea, una reducción de $93 \%$. Por otra parte, la relación entre "accidentes y violencia" y las enfermedades infecciosas muestra que en 1960 la razón de las tasas de enfermedades crónicas e infecciosas era 0,09 $(81,79 / 918,10)(13) ;$ en cambio, en 1990 la relación era $1,38(92,98 / 67,47)$, lo que equivale a decir que se invirtió por completo y que, además, ahora las causas violentas tienen una tasa de una frente a tres veces la que tienen las infecciosas.

El porcentaje de participación de cada una de las cinco causas en las muertes de cada año indica que las causas infecciosas redujeron su fuerza participativa en forma notoria, mientras las demás la aumentaron, algunas poco y otras mucho: las infecciosas causaban una de cada tres muertes (36\% de las muertes) y pasaron a responder por una de diez (menos de 9\%) muertes, mientras que las crónicas pasaron de ocasionar 21,21\% de las muertes (una de cinco) a producir $30,78 \%$ (casi una de cada tres) (13).

En resumen, la razón crónicas/infecciosas en 1960 era de 0,58 muertes por causas crónicas por cada muerte por causa infecciosa y en 1990 se presentaban 3,56 muertes por causas crónicas por cada muerte por causa infecciosa. Al comparar las muertes por causas infecciosas con las aportadas por las causas crónicas, los accidentes y las violentas, la relación en 1960 era de 0,88, mientras en 1990 la razón subió a 6,22 (13).

El "progreso" ha puesto una nota dramática: si las enfermedades crónicas aumentaron su peso en $45 \%$, los accidentes y la violencia lo incrementaron mucho más, en $111 \%$. En ese grupo, casi la totalidad de las muertes se deben a homicidios y una cifra mucho menor a accidentes de tránsito. Si bien es cierto que las muertes accidentales y violentas casi se duplicaron entre los hombres (de $16,55 \%$ llegaron a $29,96 \%$ ), entre las mujeres se triplicaron (de $5,23 \%$ a $16,02 \%$ ) (13), lo cual revela que nuestra guerra informal pero eficaz arrastró también a las mujeres en una carrera más veloz que a los hombres.

En los veinte años transcurridos entre 1975 y 1995 , la mortalidad general por homicidio en Colombia creció 3,5 veces: pasó, aproximadamente, de 24 muertes por cien mil habitantes en 1975 a 39 en 1981, a 57 en 1987, a 87 por cien mil en 1991, a 70 en 1995 y a 62 por cien mil en 2001. El grupo de edad más afectado es el de 15 a 19 años, cuya tasa de mortalidad de 1979 a 1994 se quintuplicó, seguido por el grupo de 20 a 24 años, cuya tasa se cuadruplicó $(8,9)$. La tasa general de muerte por homicidio entre las mujeres se 
triplicó entre 1979 y 1994, pasando de 3,3 a 11 por cien mil (8), pero la masculina triplicó esa tasa femenina en ambos momentos. Mirado no como riesgo sino como aporte porcentual de cada sexo al total de muertes por homicidio, puede decirse que en 1975 las mujeres contribuían casi con cero por ciento y los hombres aportaban $5 \%$ de los homicidios, pero en 1995 ellas dan cuentan de $3 \%$ de los homicidios y los hombres contribuyen con $24 \%$, de tal manera que en 1975 el cociente entre los porcentajes masculino y femenino fue de 5 y en 1994, de 8\% (8).

\section{Discusión}

La dinámica de las poblaciones o la "aritmética de la vida y de la muerte", como dice poética y precisamente Vallin (17), es sumar nacimientos vivos y restar defunciones, aunado a los egresos y llegadas por procesos migratorios, lo que deja el saldo de la población. La relación entre la natalidad o la fecundidad $y$, por otra parte, la mortalidad determinan el crecimiento natural de la población, medido por su tasa, mientras que si a tal relación natalidad-mortalidad se agrega el efecto de la migración se obtiene el crecimiento total, también expresado por una tasa.

La población de Colombia se multiplicó por 9 entre 1905 y 2005, lo cual expresa un elevado crecimiento. La densidad de la población de Colombia en 2002 era de 42 habitantes $/ \mathrm{km}^{2}$, cifra relativamente baja comparada con Costa Rica (77 $\mathrm{hab} / \mathrm{km}^{2}$ en 2002) y México (53 hab/km²), y alta frente a Argentina (14), Brasil (21), Venezuela (28) y el conjunto de América Latina y el Caribe (26 $\mathrm{hab} / \mathrm{km}^{2)}$ (30). Muy lejos estamos de las densidades de población de Francia (107 hab $/ \mathrm{km}^{2}$ : 58,5 millones en $547.030 \mathrm{~km}^{2}$ ) y Alemania (225 $\mathrm{hab} / \mathrm{km}^{2}: 83$ millones en $368.889 \mathrm{~km}^{2}$ ) y muy cerca de la de España (42,2 millones en $\left.504.790 \mathrm{~km}^{2}\right)$, que es una de las más bajas de Europa.

En otro orden de ideas, debemos pensar en lo que la poblaciones indígena y negra representan para el país, que se ufana de su composición multiétnica, pero donde cada año se reduce la proporción de tales grupos (en 1993 eran 0,32\% del total de 36 millones de habitantes). Parece elocuente el hecho de que en la Colombia "moderna", apenas en ese año de 1993 el estado haya decidido incluir tales grupos específicos en el censo nacional.

Un cambio de gran magnitud tiene consecuencias muy diferentes según ocurra en poco o mucho tiempo, es decir según su velocidad o ritmo. No es lo mismo reducir a la mitad una tasa de natalidad en 100 años que hacerlo en 30 años; ni es igual rebajar en $75 \%$ la tasa de mortalidad en 150 años que hacerlo en 75 años; más dramática será la situación si ambos fenómenos, natalidad y mortalidad, se reducen simultáneamente en poco tiempo. Una situación como esta última sucedió en Colombia.

Las modificaciones en la cantidad de personas por grupo de edad en los diferentes grupos de niños y adolescentes, y su participación porcentual en el total colombiano, son importantes pero no marcan un cambio radical en cuanto a las necesidades de atención en educación, salud y recreación. En cambio, un proceso "nuevo" en el país es el envejecimiento de la población, muy poco comparado con países como los de Europa oocidental, pero al fin de cuentas creciente entre nosotros. Ya los niños y jóvenes ( 0 a 14 años) no son la mayoría en el país, desplazados ahora por los adultos (15 a 64 años) y con notorio aumento de los ancianos (mayores de 64 años); como se anotó, por cada 100 menores de 15 años teníamos en 1964 menos de 6 viejos $(5,47)$; en 1993 eran alrededor de 12 ancianos y para 2015 serán 19, lo cual debe comprometer al país en una clara política y en programas bien estructurados de atención integral a esta población (ocupación, seguridad social, salud, recreación, etc.). No hay que olvidar que "(el) envejecimiento de la población y su significativo crecimiento en términos absolutos presenta serias implicaciones para la sociedad, en particular en países con características como las de Colombia. Tal vez la más importante de las consecuencias económicas es el efecto de la estructura sobre la proporción de dependencia; en otras palabras, cuanto mayor sea la proporción de personas adultas dependientes, tanto más difícil será para las personas en edad de producción su manutención" (31).

De gran significación social es el proceso que ha ocurrido con la llamada fuerza laboral, 
representada por el grupo de 15 a 59 años, cuyo comportamiento es similar al del grupo de 15 a 64 años. La población en edad de trabajo crece y crecerá en Colombia en los próximos decenios, y si no se crean soluciones radicales en el campo económico, el desempleo y el subempleo crecerán, tal como ha sucedido desde 1990 y los siguientes años, lo cual, por supuesto, no es un asunto solamente demográfico (aumento de las personas entre 15 y 64 años) sino, ante todo, un problema de economía política que tiene que ver esencialmente con el régimen económico vigente en el país y en el mundo, incapaz de resolver esa necesidad básica de las personas, como es el trabajo en condiciones de dignidad.

Una explicación crucial de los cambios demográficos colombianos está en la intensa modificación de la fecundidad de sus mujeres. La fecundidad (nivel y patrón) se determina principalmente por la interacción de la nupcialidad o unión (que representa la exposición al riesgo de embarazo) y de la anticoncepción. Los factores que intervienen sobre las normas y la estructura de la sociedad y su fecundidad son llamados determinantes próximos de la fecundidad y son cuatro principales: unión (nupcias, matrimonio), anticoncepción, infertilidad posparto y aborto (6). Este último no se considera, dice Flórez, por falta de información.

En Colombia, "el factor que ha jugado el papel más importante en los grandes descensos en fecundidad ha sido la anticoncepción. En contraste, los patrones de nupcialidad y de duración de la lactancia (define la infertilidad posparto) han cambiado muy poco en términos absolutos" (6). La nupcialidad afecta de manera directa a la fecundidad mediante tres factores que influyen en la exposición al riesgo de embarazo: edad de entrada a la unión, proporción de solteras, proporción de uniones disueltas (viudez, separación) (6).

Las actividades antinatalistas se iniciaron en Colombia a mediados del decenio de 1960 y han sido ejecutadas principalmente por organismos particulares, en especial por Profamilia, tras los cuales el estado ha ocultado su política antinatalista para esquivar las protestas religiosas, en particular las católicas, y para evitar entrar en confrontación con la población, que, mayoritariamente, dice ser católica. El estado montó un campo de experimentación antinatalista en Colombia, con el respaldo político y económico de los Estados Unidos de América y de las agencias internacionales sanitarias, financieras y políticas (Organización Mundial de la Salud, Fundación Kellog, Fundación Rockefeller, Banco Mundial, Fondo Monetario Internacional, Naciones Unidas). No existió entre nosotros, mujeres y hombres colombianos en ejercicio de su capacidad sexual y reproductiva, lo que se llama la "libertad reproductiva o de procreación", entendida como la "libertad concerniente a actividades y elecciones relacionadas con la procreación" (J. Robertson, citado por Brock) (32); aquí de elección poco o nada hubo, pues todo fue manipulación e imposición, aprovechando, entre otras condiciones, el analfabetismo básico y funcional, el atraso cultural, el miedo religioso y el desespero económico que agobiaba y agobia a la inmensa mayoría de colombianos.

Al lado de los cambios por el antinatalismo y absolutamente articuladas con ellos, hay que considerar las modificaciones en la unión sexual de hombres y mujeres o, como usualmente, se dice, en la familia. "La unión de pareja es el inicio de la conformación de la unidad familiar. Por lo tanto, los distintos tipos de unión implican condiciones diferentes para la constitución de una familia", afirma Flórez (6), quien agrega que "(la) relativamente baja y estable edad de la primera unión, la mayor importancia de las uniones consensuales y las transformaciones demográficas, económicas, sociales y culturales de los últimos años, explican la mayor inestabilidad que se ha observado en las últimas décadas en la familia colombiana: la proporción de separaciones y divorcios aumenta crecientemente dentro del total de uniones, al pasar de $5,5 \%$ en 1972 , al $11,7 \%$ en 1992" (6). Un problema crítico consiste en que las profundas modificaciones en la familia colombiana (estructura y función) plantean retos en todos los campos sociales.

La población colombiana en el siglo veinte ha experimentado profundos cambios epidemiológicos paralelos a las transformaciones demográficas, los cuales se expresan de muchas formas. La 
mortalidad infantil se ha reducido notoriamente, pero sigue siendo elevada si se compara con la de países que la jerga económica dominante llama "desarrollados", como Canadá y Suecia, pero también con la de otros que no encajan en tal categoría, como Cuba. El nivel de mortalidad infantil se considera uno de los indicadores de desarrollo socioeconómico, pues refleja el estado de salud de la población (6).

No hay que olvidar, sin embargo, que medir el "desarrollo socioeconómico" con un único indicador lleva fácilmente al equívoco y peor si de medir el "desarrollo humano" se trata; estos índices creados por los intelectuales, académicos y agencias del "sistema mundo capitalista", como lo llama y sustenta en su libro Sarmiento-Anzola (33), usualmente están preñados de intenciones políticas para justificar lo existente y con frecuencia "el bienestar se identifica con la producción" (33) económica, como si ésta se repartiera por igual entre los habitantes.

Desde el inicio del decenio 1971-1980, la mortalidad por enfermedades infecciosas se ha venido reduciendo en forma inequívoca, lo cual corrió simultáneo con el aumento de las llamadas "enfermedades crónicas y degenerativas" que son las dominantes desde hace varios decenios, y la peor de esas enfermedades no infecciosas ha sido la violencia, en especial el homicidio, que ha crecido durante 50 y más años. "La magnitud y persistencia de las altas tasas de homicidio en el país, especialmente focalizada en la población de hombres jóvenes, han llegado inclusive a ser observables en las variaciones de la pirámide de la población. En el último medio siglo es preocupante la reducción de la participación porcentual de los hombres entre los 15 y los 44 años, en contraste con las mujeres de la misma edad" (9). Esta violencia constituye desde hace lustros el más grave problema de salud pública en Colombia.

Aquí se han descrito y comentado someramente las grandes variaciones en las tendencias demográficas y epidemiológicas colombianas durante el siglo XX, pero quedan aplazadas las explicaciones, el debate sobre las causas 0 determinantes principales y secundarios de tales cambios. La descripción de los cambios en la población (tamaño, estructura, distribución, ritmo) y las causas de muerte (patrones de mortalidad) durante el siglo XX en Colombia es tarea laboriosa pero relativamente sencilla. Lo difícil es explicar esos cambios, decir, con argumentos sólidos, por qué se produjeron y por qué acontecieron de esa manera. No hay una regla que permita acertar $y$, además, el problema no es puramente técnico, sino que está cruzado por los enfoques políticoideológicos que se escojan, conciente o inconcientemente, enfoques que incluyen las explicaciones basadas en las supuestas "mejoras en las condiciones sociales y del ambiente" debidas al "proceso de modernización", así como la "teoría de la transición epidemiológica" y la "teoría de la transición demográfica" (6), aquella recientemente debatida y denunciada por Gómez (34) en excelente escrito.

\section{Conflicto de intereses}

El autor no tiene conflicto ni compromiso alguno con las entidades o personas aquí mencionadas. Las alusiones a unas y otras sólo buscan identificar una fuente de información o de opinión.

\section{Financiación}

Agradezco a la Universidad de Antioquia la financiación del presente trabajo, realizado dentro del plan semestral de actividades profesorales.

\section{Referencias}

1. Departamento Administrativo Nacional de Estadística. Información estadística. Censos y demografía. Series y proyecciones. Consulta: 18 nov 2004. Disponible en:_http://www.dane.gov.co/inf_est/ censo_demografia.htm y en http://www.dane.gov.co/ inf_est/series_proyecciones.htm

2. Departamento Administrativo Nacional de Estadística. Estudios censales. Bogotá: DANE; 1998.

3. Banguero H, Castellar C. La población de Colombia 1938-2025. Una visión retrospectiva y prospectiva para el país, los departamentos y sus municipios. Cali: Universidad del Valle; 1993. p.336.

4. Ministerio de Salud, Departamento Nacional de Planeación, Estudio Sectorial de Salud. La salud en Colombia. Bogotá: Ministerio de Salud; 1990. p.595.

5. Organización Panamericana de la Salud. La salud en las Américas. Washington, D.C.: OPS, Publicación Científica 569; 1998. p.184-97. Disponible en: http:// www.paho.org/spanish/HIA1998 Colombia.pdf 
6. Flórez CE. Las transformaciones sociodemográficas en Colombia durante el siglo XX. Bogotá: Tercer Mundo Editores, Banco de la República; 2000. p.181.

7. Pabón A. La mortalidad en Colombia, 1953-1991. Frecuencias por edad y sexo. Causas de defunción. Bogotá: Instituto Nacional de Salud; 1993. p.20, tablas 1 y 2.

8. Franco S. El quinto: no matar. Bogotá: Tercer Mundo Editores-Instituto de Estudios Políticos y Relaciones Internacionales (Universidad Nacional); 1999. p.82-4, 94.

9. Franco S, Forero LJ. Salud y paz en un país en guerra: Colombia, año 2002. En: Franco S, editor. La salud pública hoy. Bogotá: Universidad Nacional de Colombia; 2003. p.555-83.

10. Carmona-Fonseca J. Mortalidad por enfermedades infecciosas. Colombia, 1960-1990. En: CarmonaFonseca J, editor. Tópicos de Infectología. Medellín: Universidad de Antioquia; 1992. p.229-50.

11. Carmona-Fonseca J. La morbilidad por infecciones en Colombia, 1965-1991. Elementos para su descripción. En: Carmona-Fonseca J, editor. Tópicos de Infectología. Medellín: Universidad de Antioquia; 1993. p.219-34.

12. Carmona-Fonseca J. Perfil demográfico y epidemiológico de Colombia, 1938-1990. En: CarmonaFonseca J, editor. Tópicos de Infectología. Medellín: 1993. p.187-201

13. Carmona-Fonseca J. El contexto epidemiológico colombiano al final del siglo XX. En: Carmona-Fonseca J, editor. Tópicos de Infectología. Medellín: Universidad de Antioquia; 1999. Publicación en disco compacto.

14. Caballero C. EI DANE: artesano de los datos. Discurso en el acto de celebración de los 50 años del Dane. Bogotá, 14 octubre 2003. Consulta: 19 noviembre 2003. Disponible en: www.dane.gov.co

15. Agudelo CA. Colombia: tendencias de la población. Biomédica 1994;14:160-71.

16. Timaeus IA. Demography. En: Gail MH, Benichou J, editors. Encyclopedia of epidemiologic methods. Chichester: John Wiley \& Sons; 2000. p.296-300.

17. Vallin J. La demografía. Santiago de Chile: Centro Latinoamericano de Demografía (Celade); 1994. p.13,105-16.

18. Departamento Administrativo Nacional de Estadística. Colombia estadística 1985. Bogotá: DANE; 1986. p.118.

19. Sánchez JM. Demografía colombiana. Consulta: 1 agosto 2004. Disponible en: http://hbzones. conelprofe. com/pag_1532.html.
20. Ferrer Y. Minorías étnicas buscan su espacio en los censos. Consulta: 26 julio 2004. Disponible en: http:// www.tierramerica.net/2000/1112/noticias5.html

21. Ali MM, Cleland J, Shah IH. Trends in reproductive behavior among young single women in Colombia and Peru: 1985-1999. Demography 2003;40:659-73.

22. da Costa Leite I, Gupta N, do Nascimento Rodrigues R. Female sterilization in Latin America: cross-national perspectives. J Biosoc Sci 2004;36:683-98.

23. Ordóñez-Gómez M. La familia al final siglo en Colombia. Profamilia 1998;16:11-8.

24. Piñeros-Petersen M, Ruiz-Salguero M. Aspectos demográficos en comunidades indígenas de tres regiones de Colombia. Salud Publica Mex 1998;40:324-9.

25. Rueda JO. Dinámica de la población rural de Colombia 1951-1985. Revista de Planeación y Desarrollo 1989;21:25-46.

26. Organización Panamericana de la Salud. De datos básicos a índices compuestos: una revisión del análisis de mortalidad. Boletín Epidemiológico OPS 2002;23:1-2.

27. Arriaga EE. Los años de vida perdidos: su utilización para medir el nivel y cambio de la mortalidad. Notas de Población CELADE 1996;24:7-38.

28. Ministerio de Salud. La carga de la enfermedad en Colombia. Bogotá: Ministerio de Salud;1994. p.187.

29. Ministerio de Salud. Mortalidad y años de vida ajustados por discapacidad como medida de la carga de la enfermedad. Colombia, 1985-1995. Bogotá: Ministerio de Salud; 1999. p. 97.

30. World Bank. World Development Report 2004: making services work for poor people. Consulta: 13 enero de 2005. Disponible en:_http://econ.worldbank.org/files/ 30042_select.pdf.

31. Chiappe ML. Demografía actual: proyecciones sobre la menopausia y el climaterio en Colombia. Mayo 1995. Consulta: 1 agosto 2004. Disponible en: http:// www.encolombia.com/medicina/menopausia/ meno1295-aspectosocial.htm.

32. Brock DW. Libertad reproductiva: naturaleza, bases y límites. En: Platts $M$, editor. Dilemas éticos. México: Fondo de Cultura Económica; 1997. p.51-2.

33. Sarmiento-Anzola L. Sistema mundo capitalista. Fábrica de riqueza y de miseria. Bogotá: Ediciones Desde Abajo; 2004. p. 223

34. Gómez RD. La transición en epidemiología y salud pública: ¿explicación o condena? Revista Facultad Nacional de Salud Pública (Medellín) 2001;19:557-74. 